\title{
LABORATORY TRIALS OF COLD RECYCLED FOAMED BITUMEN ASPHALT: RAF WADDINGTON
}

Helena Isabel Lacalle Jiménez, URS Infrastructure \& Environmental UK Limited, 12 Regan Way, Chetwynd Business Park, Chilwell, Nottingham NG9 6RZ, UK. Email: helena.lacalle@urs.com

Jessica Tuck, URS Infrastructure \& Environmental UK Limited, 12 Regan Way, Chetwynd Business Park, Chilwell, Nottingham NG96RZ,UK. Email: jessica.tuck@urs.com

doi: 10.1515/ijpeat-2015-0005

\section{Abstract}

The Defence Infrastructure Organisation requested a pavement evaluation on RAF Waddington and the results indicated that runway rehabilitation and reprofiling was needed in order to meet the physical design requirements set out in the Manual of Aerodrome Design \& Safeguarding. The presence of tar in a layer of the old pavement promoted the option of cold recycling this material into the new structure. This paper presents the results from a laboratory investigation into the suitability of cold recycled foamed bitumen asphalt to be used in the structural layers of an airfield pavement.

Laboratory mixture designs with foamed bitumen, incorporating asphalt planings from RAF Waddington runway, were produced in URS Infrastructure and Environment Ltd. laboratory. Specimens were used to assess mix performance and in order to add confidence to the design. The last objective of the research was to demonstrate that asphalt planings from RAF Waddington could be recycled into foamed asphalt for incorporation in the runway rehabilitation works. The optimum binder content was determined from Indirect Tensile Stiffness Modulus tests and Indirect Tensile Strength tests, concluding that the optimum binder content was 3.3\% by mass. As a common practice in the UK, up to $1.5 \%$ by mass of cement was added to the mixture to improve early life performance. To assess the foamed bitumen samples' performance with time, specimens were prepared and cured for 28, 180 and 360 days at different temperatures. Post curing, the specimens were tested for a range of performance criteria including fatigue, stiffness and durability.

The study found that asphalt sampled from the runway at RAF Waddington can be recycled into foamed asphalt, meeting the requirements of Defence Infrastructure Organisation Specification 050.

\section{Introduction}

A pavement evaluation on RAF Waddington was undertaken by URS in June 2012 which highlighted the need for Runway Rehabilitation and Reprofiling. High levels of Polycyclic Aromatic Hydrocarbons (PAH) were identified in this evaluation, which highlighted the presence of tar. This presented some limitations on recycling and expensive cost of disposal, for this reason, and because Cold Recycled Bound Materials (CRBM) were successfully used in other schemes, the potential for incorporation of foamed asphalt in the runway renewal scheme was explored. 
Use of foam mix asphalt in the runway would be a UK first; therefore, a laboratory recycling trial was carried out by URS in order to add confidence and demonstrate that site won materials could be recycled into foamed asphalt to meet the requirements of the specifications.

This paper presents results of the recycling study that assesses the performance of laboratory manufactured CRBM incorporating reclaimed asphalt taken from the runway at Waddington.

The pavement evaluation report (URS, June 2012) identified that the construction of the pavement was typically asphalt between 315 and $410 \mathrm{~mm}$ in thickness overlying $210 \mathrm{~mm}$ thickness of pavement quality concrete (PQC) or dry lean concrete (DLC) layer. In some areas of the runway, the lower layers of the asphalt were found to contain high levels of PAH, the depth of these vary in thickness between $225 \mathrm{~mm}$ and $280 \mathrm{~mm}$.

At time of commencement of this study it was not clear whether non-tar material would be incorporated in the runway refurbishment, therefore two material designs were assessed: one with Reclaimed Asphalt Planings (RAP) containing tar (herein "tar bound (Bottom RAP) mixture") and the other for material free of tar (herein "non-tar bound (Top RAP) mixture").

A three stage laboratory study was undertaken:

- Stage 1: Confirm recyclability of the materials

- Stage 2: Mixture testing to determine optimum binder content

- Stage 3: Mixture testing to assess CRBM mixture performance

This laboratory program aimed to provide mixture performance results with a view to developing CRBM runway design and material specifications in the future. The study comprised a phased approach, with the three laboratory study stages outlined in this paper.

\section{Literature Review}

The UK has adopted the concept of sustainable development and two key measurements of the level of sustainability achieved are the volumes of new resources consumed and the waste sent for disposal. The aim should be to minimise the waste generated and maximise the quantities of materials reused or recycled. Using recycled materials not only avoids waste generation but also the equivalent use of primary materials (CIRIA 1999).

Recycling asphalt is a pavement rehabilitation technique which involves reusing materials from the layers constituting a pavement that has already been in service, materials that have lost some of their original properties because of use or ageing, such as cohesion, texture and composition, but have the potential for being reused and forming new layers. 
This material recovered from aged asphalt pavements is known as RAP and is one of the most important elements to bear in mind during the recycling process as it has great influence on the end product characteristics.

When the use of RAP is the selected option for pavement rehabilitation, the next step is to identify the recycling agent to be used. These agents have the purpose of altering the properties of old or aged binders and can be classified as softening agents or rejuvenating agents. The difference between these two types of agents are that softening agents only lower the binder viscosity while rejuvenating agents restore the physical and chemical properties of the aged binder. Foamed bitumen is used as rejuvenator.

Foamed bitumen is produced by injecting air and water droplets under a high pressure (5 bars) into hot $\left(160-180^{\circ} \mathrm{C}\right)$ liquid bitumen, resulting in bitumen taking the form of foam as schematically illustrated in Figure 1. The volume of bitumen will increase while viscosity considerably reduces (Jitareekul 2009).

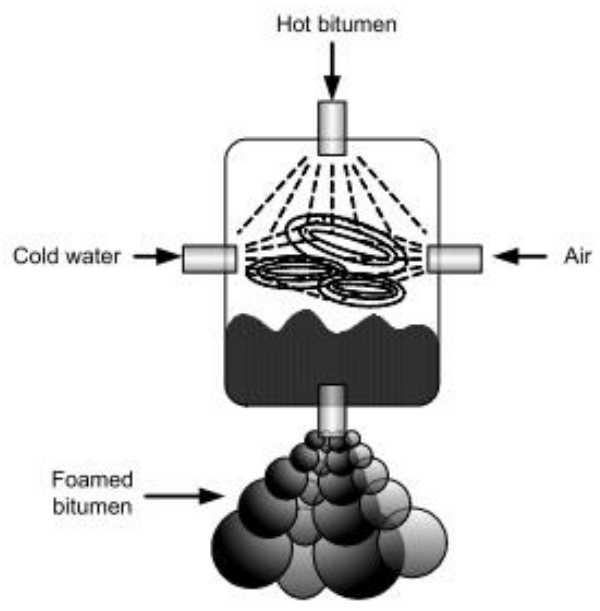

Figure 1 Foamed bitumen production

Normally between $3 \%$ and $5 \%$ of foam bitumen is added, but when the recycled material contains a high proportion of bitumen, this can be reduced to $2 \%$ or $3 \%$ ('Lanre 2010), (Jitareekul 2009), (Botasso et al. 2008).

Foamed bitumen has been used with success in several sites, having similar strength and stiffness that conventional hot mixes after a period of curing, and giving the pavement a good structural performance (Sunarjono 2008).

The design guide and specifications used in the UK for road maintenance is the TRL Report TRL611. For Airfields there is the Specification 050 "Recycled bound materials for airfields".

\section{Stage 1: Recyclability and Waste Acceptance Criteria}

Asphalt layers of each of the cores taken from the runway during the pavement evaluation were tested with PAK-Marker, sprayed in a thin layer along the length of the core sample. After allowing the spray to dry the colour is assessed. The spray remains white in colour if sample has no polycyclic aromatic compounds, whilst a yellow colour is produced if high quantities of PAHs are present. It was found that 
bituminous samples from the top (approximately 200mm) of the pavement in general did not show a positive result for PAH when tested with the PAK-marker. However, in some areas of the runway, the lower layers of the asphalt showed positive results indicative of the presence of tar. The layers containing tar were sent to a laboratory for Waste Acceptance Criteria (WAC) testing to confirm the levels of PAH and Benzo(a)pyrene. The results from this analysis are summarised in Table 1.

Table 1. PAH results from WAC testing (from the lower asphalt layers)

\begin{tabular}{|c|c|c|c|}
\hline Material & PAH (mg/kg) & $\begin{array}{c}\text { Benzo(a)pyrene } \\
(\mathbf{m g} / \mathbf{k g})\end{array}$ & \begin{tabular}{c} 
Implications \\
\cline { 2 - 4 }
\end{tabular} \\
\cline { 2 - 4 } & $>25$ & NA & $\begin{array}{c}\text { Not recycled into } \\
\text { hot mix asphalt }\end{array}$ \\
\hline \multirow{2}{*}{ Limitations } & $>1000$ & $>100$ & $\begin{array}{c}\text { Not recycled into } \\
\text { unbound } \\
\text { applications. } \\
\text { Classified as } \\
\text { Hazardous waste if } \\
\text { disposed }\end{array}$ \\
\cline { 2 - 4 } & NA & $>50$ & $\begin{array}{c}\text { Classified as } \\
\text { Hazardous Waste } \\
\text { and denoted as } \\
\text { bituminous mixtures } \\
\text { containing coal tar }\end{array}$ \\
\hline $\begin{array}{c}\text { Tar bound (Bottom RAP) } \\
\text { mixture }\end{array}$ & 64000 & 3000 & $\begin{array}{c}\text { Cannot be recycled } \\
\text { into hot mix or } \\
\text { unbound material. } \\
\text { Classified as } \\
\text { Hazardous waste if } \\
\text { disposed. }\end{array}$ \\
\hline
\end{tabular}

The limitations for recycling bituminous materials are summarised:

- Bituminous materials with PAH over $25 \mathrm{mg} / \mathrm{kg}$ shall not be recycled into hot mix asphalt (County Surveyors Society Guidance Note 2008).

- Bituminous materials with PAH over $1000 \mathrm{mg} / \mathrm{kg}$ and benzo(a)pyrene levels above $100 \mathrm{mg} / \mathrm{kg}$ are not permitted to be recycled into unbound applications (County Surveyors Society Guidance Note 2008).

- The acceptable threshold values of Total PAH and Benzo(a)pyrene are 1000 $\mathrm{mg} / \mathrm{kg}$ and $100 \mathrm{mg} / \mathrm{kg}$ respectively. Above these limits material is classed as hazardous waste if disposed of (The Stationery Office 2005).

- The Environment Agency considers that if benzo[a]pyrene is present at a concentration of $50 \mathrm{mg} / \mathrm{kg}$ or more in the asphalt arisings (excluding any other waste material), the waste should be classed as hazardous and denoted by the EWC code 170301 (bituminous mixtures containing coal tar) (ADEPT 2013).

This confirms that if disposed of, it is likely that the lower layers of the original runway pavement would be classified as Hazardous Waste, leading to a high disposal cost. In addition, this material cannot be recycled into hot mix asphalt or unbound material. Recycling into cold recycled bound material is permitted and is likely to offer a cost effective and viable engineering solution. 


\section{Stage 2: Mixture Testing to Determine Optimum Binder Content}

To determine optimum binder content of the foamed mixture a sample preparation and mixing technology was developed.

\section{Sample Preparation}

Ten large 450mm diameter cores were taken from RAF Waddington runway and were separated into tar and non-tar containing layers. Then the samples were processed through a jaw crusher and graded (results are presented in Table 2).

Table 2. Initial particle size distribution

\begin{tabular}{|c|c|c|c|}
\hline \multirow{2}{*}{$\begin{array}{c}\text { Sieve size } \\
(\mathbf{m m})\end{array}$} & $\begin{array}{c}\text { Non-tar bound (Top RAP) } \\
\text { mixture }\end{array}$ & $\begin{array}{c}\text { Tar bound (Bottom RAP) } \\
\text { mixture }\end{array}$ & $\begin{array}{c}\text { Specification } \\
\text { (min.-max.) }\end{array}$ \\
\hline $\mathbf{2 0}$ & 100 & 100 & 100 \\
\hline $\mathbf{1 4}$ & 100 & 100 & $85-100$ \\
\hline $\mathbf{1 0}$ & 88 & 94 & $68-95$ \\
\hline $\mathbf{4}$ & 6 & 53 & $38-69$ \\
\hline $\mathbf{2}$ & 0.3 & 36 & $26-53$ \\
\hline $\mathbf{0 . 5}$ & 0.2 & 16 & $13-33$ \\
\hline $\mathbf{0 . 2 5}$ & 0.1 & 5.2 & $9-25$ \\
\hline $\mathbf{0 . 0 6 3}$ & 0 & 0.6 & $5-20$ \\
\hline
\end{tabular}

The RAP was then split into $0 / 4 \mathrm{~mm}$ and $4 / 20 \mathrm{~mm}$ size fractions. Each fraction was graded to BS EN 933-1 and a blend of the size fractions was calculated which targeted the specified grading curve. The bottom end of the grading did not meet the specifications. To solve this, the Non-tar bound (Top RAP) mixture was mixed with Crushed Rock Fines (CRF) and Fly Ash (FA) and for the Tar bound (Bottom RAP) mixture only FA was needed. The mix design and final grading achieved with the addition of CRF and FA to meet the specification are presented in Table 3 and Table 4.

Table 3. Mix design to determine optimum binder content

\begin{tabular}{c|c|c|c|c|}
\multirow{2}{*}{ Constituent } & Supplier & Source/Product & $\begin{array}{c}\text { Non-tar bound } \\
\text { (Top RAP) } \\
\text { mixture }\end{array}$ & $\begin{array}{c}\text { Tar bound } \\
\text { (Bottom RAP) } \\
\text { mixture }\end{array}$ \\
\hline Bitumen & Nynas & Nyfoam 100 & Varied 3 - 3.6\% & Varied 3-3.6\% \\
\hline Cement & Cemex & $\begin{array}{c}\text { CEM I }(52.5 \mathrm{kN}), \\
\text { Rugby }\end{array}$ & $1 \%$ & $1 \%$ \\
\hline CRF & Lafarge Tarmac & Mountsorrel Granite & $30 \%$ & $0 \%$ \\
\hline FA & $\begin{array}{c}\text { Cottam power } \\
\text { Station }\end{array}$ & Conditioned FA & $5.8 \%$ & $4.8 \%$ \\
\hline RAP & $\begin{array}{c}\text { Derived from site } \\
\text { cores }\end{array}$ & RAF Waddington & $52 \%$ & $93 \%$ \\
\hline Water & N.A & N.A & $4.1 \%$ & $4.1 \%$ \\
\hline
\end{tabular}


Table 4. Final particle size distribution

\begin{tabular}{|c|c|c|c|}
\multirow{2}{*}{$\begin{array}{c}\text { Sieve size } \\
(\mathbf{m m})\end{array}$} & $\begin{array}{c}\text { Non-tar bound (Top RAP) } \\
\text { mixture }\end{array}$ & $\begin{array}{c}\text { Tar bound (Bottom RAP) } \\
\text { mixture }\end{array}$ & $\begin{array}{c}\text { Specification } \\
\text { (min.-max.) }\end{array}$ \\
\hline $\mathbf{2 0}$ & 100 & 100 & 100 \\
\hline $\mathbf{1 4}$ & 91.2 & 95.9 & $85-100$ \\
\hline $\mathbf{1 0}$ & 75.7 & 86.6 & $68-95$ \\
\hline $\mathbf{4}$ & 51.3 & 54.1 & $38-69$ \\
\hline $\mathbf{2}$ & 32.1 & 30.2 & $26-53$ \\
\hline $\mathbf{0 . 5}$ & 16.1 & 14.7 & $13-33$ \\
\hline $\mathbf{0 . 2 5}$ & 12.0 & 11.4 & $9-25$ \\
\hline $\mathbf{0 . 0 6 3}$ & 8.6 & 8.4 & $5-20$ \\
\hline
\end{tabular}

Wirtgen classify the bitumen in the RAP as being "active" or "inactive", as described in the Wirtgen Manual (Wirtgen GmbH 2012). To investigate the state of the bitumen in the RAP, it was tested following the Wirtgen Manual methodology. As a rule, "active" RAP contains sticky, shiny bitumen whilst "inactive" RAP is dull black rock. For this test, RAP was heated to $70{ }^{\circ} \mathrm{C}$ and a $100 \mathrm{~mm}$ Marshal plug manufactured. Samples were then soaked in water for 24 hours and Indirect Tensile Strength (ITS) test was carried out. Samples with ITS values higher than $100 \mathrm{kPa}$ were considered "active". Results are presented in Table 5.

Table 5. RAP classification

\begin{tabular}{|c|c|c|}
\hline RAP layer & ITS results & Classification \\
\hline Non-Tar bound (Top RAP) mixture & $468 \mathrm{kPa}$ & Active \\
\hline Tar bound (bottom RAP) mixture & Sample does not hold together & Inactive \\
\hline
\end{tabular}

This results show that the newest bitumen is still active and it has to be taken into account when studying the optimum binder content. It also has implications in the grading, as the lack of fines in the Non-Tar bound (Top RAP) mixture observed and presented in Table 2 is likely to be due to the "active" bitumen holding the fine particles.

\section{Laboratory Mixing Methodology}

The mix design and testing was carried out by URS laboratory in Nottingham and comprised the following stages:

1. Foaming the bitumen: A Wirtgen WLB10 was used as the foam generator. The foamed bitumen expansion ratio, half-life and injection mass were optimised and tested prior to the commencement of mixing.

Nyfoam 100 bitumen supplied by Nynas was used to produce the foam, with an air pressure of 5 bar, a water pressure of 4 bar and bitumen temperature of $170^{\circ} \mathrm{C}$, as suggested by Nynas based on past experience. An investigation into the effect of water content on half-life and expansion ratio was carried out to determine the optimum water content required to achieve a half-life greater than six seconds and an expansion ratio greater than 8 (Wirtgen GmbH 2012).

Figure 2 provides a summary of the results from this investigation and shows that the optimum water content in the bitumen is between 1 and $1.6 \%$ water. 


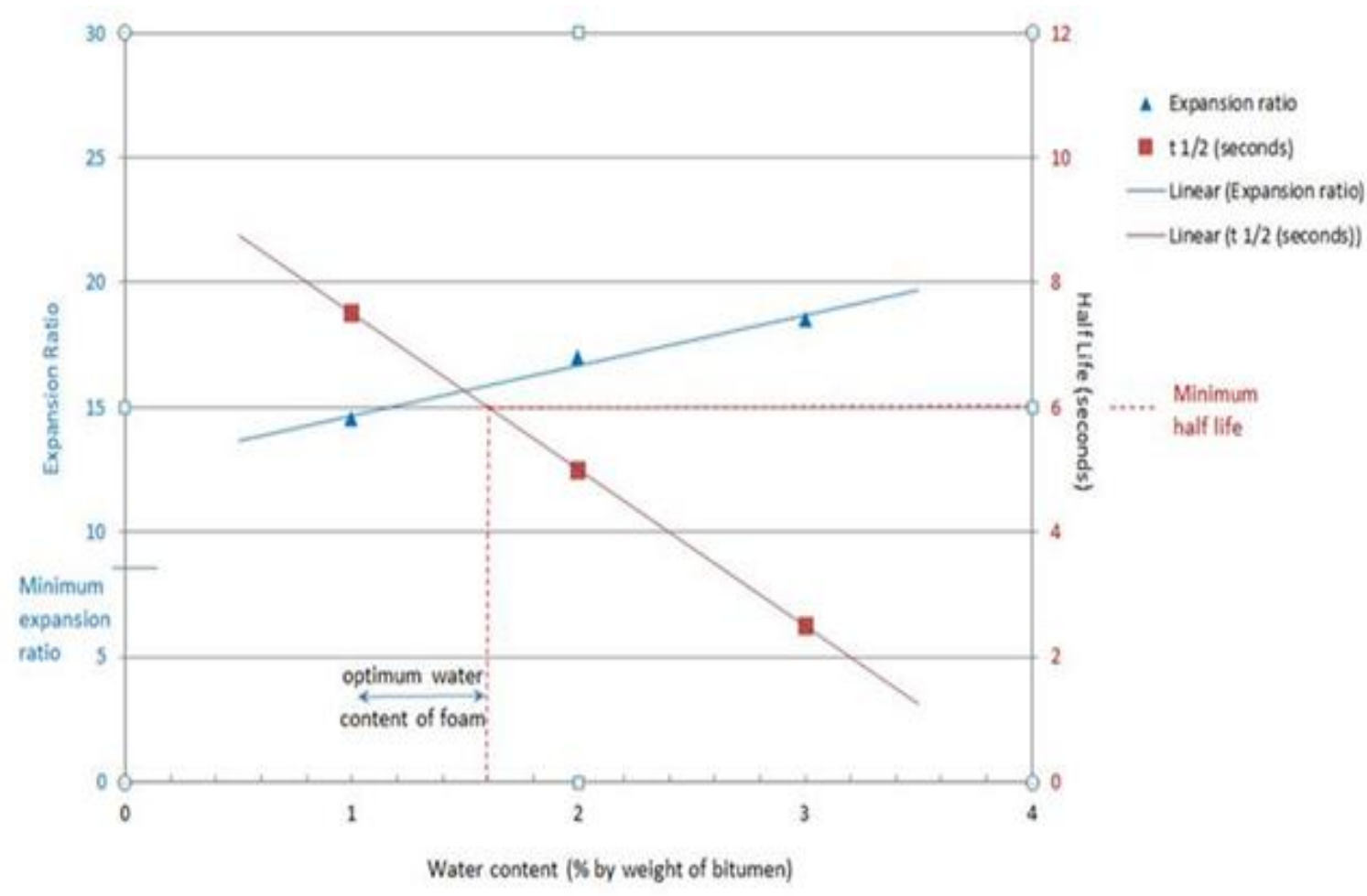

Figure 2. Influence of water content on bitumen foaming properties

2. Aggregate constituents were weighed in the correct proportions to achieve the target grading curve.

3. The aggregate constituents were mixed for two minutes in a Wirtgen WLM30 mixer. Water was added until aggregates reached their target moisture content which is known as the "fluff point"(Wirtgen GmbH 2012), where there are no dry fines in the mix and the mix holds together when squeezed by hand. The mass of added water was recorded.

4. Foamed bitumen was injected into the mixer and mixed for two minutes.

5. Any visible balls of bitumen and fines were broken down by hand and mixed for a further minute.

6. Test specimens were compacted within two hours of mixing.

7. Compacted specimens were double wrapped in cling film and sealed in a bag in their modulus for curing at $40^{\circ} \mathrm{C}$ for 28 days.

8. After curing, Indirect Tensile Stiffness Modulus (ITSM) to BS EN 1269726:2004 Annex C and Indirect Tensile Strength (ITS) to BS EN 1269723:2003 were determined to establish the optimum binder content.

\section{Testing to Determine Optimum Binder Content}

Foamed asphalt mixtures were produced as described above at three different bitumen additions: $3.0,3.3$ and $3.6 \%$ bitumen. $1 \%$ cement content was set for the initial mixtures to improve curing and total strength of the specimens. Results of the laboratory work are presented in Table 6. The average ITSM is calculated with 6 samples and the average ITS with 3 samples. 
Table 6. Test results for samples cured at $40^{\circ} \mathrm{C}$ for 28 days

\begin{tabular}{|c|c|c|c|c|c|c|c|}
\hline \multirow[t]{2}{*}{ Bitumen content } & \multicolumn{3}{|c|}{$\begin{array}{c}\text { Tar bound } \\
\text { (Bottom RAP) mixture }\end{array}$} & \multicolumn{3}{|c|}{$\begin{array}{c}\text { Non-tar bound } \\
\text { (Top RAP) mixture }\end{array}$} & \multirow{2}{*}{$\begin{array}{c}\text { Specification } \\
\text { Min 3.0\% } \\
\end{array}$} \\
\hline & $3.0 \%$ & $3.3 \%$ & $3.6 \%$ & $3.0 \%$ & $3.3 \%$ & $3.6 \%$ & \\
\hline $\begin{array}{c}\text { Average } 28 \text { day ITSM } \\
\text { (MPa) }\end{array}$ & 920 & 3650 & 3405 & 3327 & 3528 & 3010 & 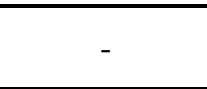 \\
\hline Average ITS (kPa) & 112 & 322 & 324 & 159 & 321 & 160 & $>250$ \\
\hline Water sensitivity ratio & 1.5 & 1.0 & 1.0 & 0.9 & 1.0 & 1.1 & $>0.8$ \\
\hline Bulk Density $\left(\mathrm{kg} / \mathrm{m}^{3}\right)$ & 2123 & 2139 & 2111 & 2126 & 2146 & 2164 & - \\
\hline$\underset{\left(\mathrm{kg} / \mathrm{m}^{3}\right)}{\text { Maximum density }}$ & \multicolumn{3}{|c|}{2346} & \multicolumn{3}{|c|}{2341} & - \\
\hline
\end{tabular}

Results suggest that $3.3 \%$ added bitumen content is the optimum for both the non-tar bound (Top RAP) mixture and the tar-bound (Bottom RAP) mixture. Although having "active" bitumen in the non-tar bound (Top RAP) mixture, the addition of CRF reduces the overall bitumen content in the aggregate, this could explain why both materials have the same optimum binder content.

Asphalt material stiffness relates to its load spreading ability, one of the key parameters used to assess pavement structural condition. In a structural layer, high stiffness indicates good load-spreading ability.

The ITSM values rise from $3.0 \%$ bitumen to $3.3 \%$ bitumen and then lower for the $3.6 \%$ bitumen. This could be due to having insufficient bitumen to bind the mixture in the first case and having too much bitumen in the second case what gives lower stiffness values to the mixture. The distribution of the bitumen or mixing efficiency could also be a possible contributing factor to variation on results.

The ITS test is an indirect measure of the tensile strength and reflects the flexibility and flexural characteristics of the mixture. It is an economic method for investigation the effectiveness of the bitumen (Wirtgen $\mathrm{GmbH}$ 2012). This method was added to the investigation since the ITSM results can be distorted with the addition of cement, making the mixture stiff enough to meet the stiffness specification but may not be a well graded, well mixed cohesive mixture.

ITS values were found to be below the required value for mixtures at $3.0 \%$ and $3.6 \%$ bitumen (for the non-tar bound (Top RAP) mixture only). This is likely to be due to the bitumen content and potentially poor distribution of bitumen, which was evident based on visual assessment. In order to improve the non-tar mixture, the proportion of CRF in the non-tar mixture was reduced during stage 3.

\section{Stage 3: Mixture Testing to Assess CRBM Mixture Performance}

Test specimens were produce at $3.3 \%$ added bitumen content and $1.5 \%$ cement content. The cement content was increased from 1.0\% used in Stage 2, to $1.5 \%$ in order to replicate common practice for foamed asphalt mixtures in the UK. In addition, the constituent proportions for the non-tar bound (top RAP) mixture were adjusted in order to reduce the proportion of CRF contained in the mixture and maximise the recycled content, improving ITS results. The mixture proportions are summarised in Table 7. 
Table 7. Constituent proportions for stage 3

\begin{tabular}{|c|c|c|}
\multirow{2}{*}{ Ingredient } & \multicolumn{2}{|c|}{ Constituent proportion (by dry mass) } \\
\cline { 2 - 3 } & Tar bound (Bottom RAP) mixture & Non-tar bound (Top RAP) mixture \\
\hline Bitumen & $3.3 \%$ & $3.3 \%$ \\
\hline Cement & $1.5 \%$ & $1.5 \%$ \\
\hline RAP & $88.0 \%$ & $71.6 \%$ \\
\hline Crushed rock fines & $0 \%$ & $17.4 \%$ \\
\hline Fly ash & $7.2 \%$ & $6.2 \%$ \\
\hline Total water & $4.5 \%$ & $4.5 \%$ \\
\hline
\end{tabular}

119 samples were prepared as described in Stage 2, and cured at different temperatures $\left(20^{\circ} \mathrm{C}\right.$ and $\left.40^{\circ} \mathrm{C}\right)$ over varied times $(28,180$ and 360 days).

The testing methodology comprised:

- Determination of ITSM to BS EN 12697-26:2004 Annex C, to assess the load spreading ability and durability after wet conditioning immersed at $20^{\circ} \mathrm{C}$ for 7 days (immediately following the curing period).

- Determination of the ITS to BS EN 12697-23:2003 before and after wet conditioning immerse in water at $20^{\circ} \mathrm{C}$ for 24 hours (immediately following the curing period).

- Determination of Indirect Tensile Fatigue (ITF)(British Board of Agreement n.d.). Fatigue performance of a material is one of the key parameters used to assess a pavement's expected life. The fatigue test is undertaken at several stress conditions, with the number of loading cycles to failure recorded. This enables a predicted 'fatigue life' to be calculated and plotted.

Laboratory test results are summarised in Tables 8 and 9.

Table 8. Laboratory mixtures results summary for samples cured at $40^{\circ} \mathrm{C}$

\begin{tabular}{|c|c|c|c|c|c|}
\hline \multirow{2}{*}{$\begin{array}{l}\text { Material } \\
\text { property }\end{array}$} & \multirow{2}{*}{$\begin{array}{c}\text { Tar bound } \\
\begin{array}{c}\text { (bottom RAP) } \\
\text { mixture }\end{array} \\
28 \text { days }\end{array}$} & \multicolumn{3}{|c|}{ Non-tar bound (top RAP) mixture } & \multirow{2}{*}{$\begin{array}{l}\text { Specification } \\
\text { Requirement } \\
\text { (at } 28 \text { days only) }\end{array}$} \\
\hline & & $72 \mathrm{~h}$ & 14 days & 28 days & \\
\hline ITSM (MPa) & $\begin{array}{c}4812 \\
(4370-5390)\end{array}$ & - & $\begin{array}{c}3483 \\
(3070-4220)\end{array}$ & $\begin{array}{c}5090 \\
(4400-5940)\end{array}$ & $\begin{array}{c}3,500(\min ) \\
10,000(\max )\end{array}$ \\
\hline $\begin{array}{c}\text { Moisture } \\
\text { sensitivity } \\
\text { (retained } \\
\text { stiffness) }\end{array}$ & 0.97 & - & - & 0.95 & 0.8 minimum \\
\hline ITS (kPa) & $\begin{array}{c}364 \\
(340-408)\end{array}$ & $\begin{array}{c}274 \\
(259-288)\end{array}$ & - & $\begin{array}{c}138 \\
(132-145)\end{array}$ & $>225$ at 28 days \\
\hline ITS $_{\text {wet }}(\mathbf{k P a})$ & $\begin{array}{c}300 \\
(265-347)\end{array}$ & - & - & $\begin{array}{c}193 \\
(155-231)\end{array}$ & Information only \\
\hline $\begin{array}{l}\text { Bulk density } \\
\qquad\left(\mathrm{kg} / \mathrm{m}^{3}\right)\end{array}$ & $\begin{array}{c}2098 \\
(2085-2124)\end{array}$ & - & $\begin{array}{c}2104 \\
(2086-2131)\end{array}$ & $\begin{array}{c}2104 \\
(2086-2131)\end{array}$ & Information only \\
\hline
\end{tabular}

Note: Values shown are mean (with minimum and maximum values in brackets). 
Table 9. Laboratory mixture results summary for samples cured at $20^{\circ} \mathrm{C}$

\begin{tabular}{|c|c|c|c|c|c|c|}
\hline \multirow{2}{*}{$\begin{array}{l}\text { Material } \\
\text { property }\end{array}$} & \multicolumn{3}{|c|}{ Tar bound (bottom RAP) mixture } & \multicolumn{3}{|c|}{ Non-tar bound (top RAP) mixture } \\
\hline & 28 days & 180 days & 360 days & 28 days & 180 days & 360 days \\
\hline ITSM (MPa) & $\begin{array}{c}2915 \\
(2200-3420)\end{array}$ & $\begin{array}{l}4515 \\
(3820- \\
5590)\end{array}$ & $\begin{array}{l}4763 \\
(4400- \\
5190)\end{array}$ & $\begin{array}{c}3028 \\
(2810-3580)\end{array}$ & $\begin{array}{c}4146 \\
(3980-4410)\end{array}$ & $\begin{array}{c}4908 \\
(4450-5580)\end{array}$ \\
\hline $\begin{array}{c}\text { Moisture } \\
\text { sensitivity } \\
\text { (retained } \\
\text { stiffness) }\end{array}$ & 1.01 & 1.08 & 0.87 & 0.91 & 0.94 & 0.83 \\
\hline ITS (kPa) & $\begin{array}{c}285 \\
(242-339)\end{array}$ & $\begin{array}{c}384 \\
(318-449)\end{array}$ & $\begin{array}{c}467 \\
(409-511)\end{array}$ & $\begin{array}{c}116 \\
(109-125)\end{array}$ & $\begin{array}{c}444 \\
(394-497)\end{array}$ & $\begin{array}{c}261 \\
(225-314)\end{array}$ \\
\hline ITS $_{\text {wet }}(\mathbf{k P a})$ & $\begin{array}{c}239 \\
(205-261)\end{array}$ & $\begin{array}{c}351 \\
(339-362)\end{array}$ & $\begin{array}{c}453 \\
(407-537)\end{array}$ & $\begin{array}{c}156 \\
(126-184)\end{array}$ & $\begin{array}{c}227 \\
(220-238)\end{array}$ & $\begin{array}{c}209 \\
(195-237)\end{array}$ \\
\hline TSR & $84 \%$ & $91 \%$ & $97 \%$ & $134 \%$ & $51 \%$ & $80 \%$ \\
\hline $\begin{array}{l}\text { ITFT linear } \\
\text { regression } \\
\text { line }\end{array}$ & $\begin{array}{l}3.27-0.30 \log \\
\text { (cycles to } \\
\text { failure) } \\
\mathrm{R}^{2}=0.9\end{array}$ & $\begin{array}{c}2.67-0.13 \\
\log \text { (cycles } \\
\text { to failure) } \\
\mathrm{R}^{2}=0.65\end{array}$ & $\begin{array}{c}2.77-0.15 \\
\log \text { (cycles } \\
\text { to failure) } \\
\mathrm{R}^{2}=0.98\end{array}$ & $\begin{array}{c}2.84-0.15 \\
\log (\text { cycles to } \\
\text { failure) } \\
\mathrm{R}^{2}=0.9\end{array}$ & $\begin{array}{c}2.69-0.15 \\
\log (\text { cycles to } \\
\text { failure) } \\
\mathrm{R}^{2}=0.69\end{array}$ & $\begin{array}{c}2.82-0.20 \\
\log \text { (cycles to } \\
\text { failure) } \\
\mathrm{R}^{2}=0.76\end{array}$ \\
\hline $\begin{array}{c}\text { Bulk density } \\
\left(\mathbf{k g} / \mathrm{m}^{3}\right)\end{array}$ & $\begin{array}{c}2084 \\
(2063-2109)\end{array}$ & $\begin{array}{l}2092 \\
(2076- \\
2147)\end{array}$ & $\begin{array}{l}2106 \\
(2080- \\
2129)\end{array}$ & $\begin{array}{c}2095 \\
(2068-2131)\end{array}$ & $\begin{array}{c}2080 \\
(2061-21.3)\end{array}$ & $\begin{array}{c}2106 \\
(2088-2121)\end{array}$ \\
\hline
\end{tabular}

Note: Values shown are mean (with minimum and maximum values in brackets).

Comparing ITSM and ITS results from both tables it can be said that samples cured at $40^{\circ} \mathrm{C}$ for 28 days showed similar results to those of samples cured at $20^{\circ} \mathrm{C}$ for 360 days. Curing samples in the laboratory is an area of ongoing research, which is developing as the relative long term performance of these mixtures is being furthered.

The ITSM and moisture sensitivity results are within specification limits and suggest that the samples are not moisture susceptible.

Some ITS values from Non-tar bound (top RAP) mixture are below the specifications requirements. A possible explanation could be due to poor bitumen distribution in the mixture, associated with the presence of CRF.

The fatigue test is undertaken at several stress conditions, with the number of loading cycles to failure recorded. This enables a predicted 'fatigue life' to be calculated and plotted. Fatigue performance of the non-tar bound (Top RAP) mixture is not very consistent as reflected by the low values of $\mathrm{R}^{2}$. This can be due to the poor mixture of the bitumen addressed before.

In order to quantify the differences in fatigue characteristics between the mixtures, the number of cycles to failure can be calculated at particular strain levels with the linear regression line. For asphalt pavements, analyses confirmed by measurements have shown that the tensile strain at the base of the bound layers, under a moving wheel load, is of the order of 100 microstrain (Cooper \& Pell 1974).

In Table 10 the calculated cycles to failure are presented, and in 
Figure 3 the fatigue lines for samples cured at $20^{\circ} \mathrm{C}$ for 360 days and two standard asphalt materials for comparison purposes are plotted.

Table 10. Calculated fatigue for 100 microstrain

\begin{tabular}{|c|c|}
\hline Material & $\begin{array}{c}\text { Fatigue Life (Number of Cycles to Failure) } \\
\text { at Tensile Strain }=100 \mu \varepsilon\end{array}$ \\
\hline $\begin{array}{c}\text { Tar bound (Bottom RAP) mixture after } 28 \text { days } \\
\text { curing at } 40^{\circ} \mathrm{C}\end{array}$ & 17,113 \\
\hline $\begin{array}{l}\text { Tar bound (Bottom RAP) mixture after } 180 \\
\text { days cured at } 20^{\circ} \mathrm{C}\end{array}$ & 142,510 \\
\hline $\begin{array}{c}\text { Tar bound (Bottom RAP) mixture after } 360 \\
\text { days curing at } 20^{\circ} \mathrm{C}\end{array}$ & 135,935 \\
\hline $\begin{array}{c}\text { Non-tar bound (Top RAP) mixture after } 28 \\
\text { days curing at } 40^{\circ} \mathrm{C}\end{array}$ & 13,335 \\
\hline $\begin{array}{c}\text { Non-tar bound (Top RAP) mixture after } 180 \\
\text { days cured at } 20^{\circ} \mathrm{C}\end{array}$ & 39,810 \\
\hline $\begin{array}{c}\text { Non-tar bound (Top RAP) mixture after } 360 \\
\text { days curing at } 20^{\circ} \mathrm{C}\end{array}$ & 10,826 \\
\hline $\begin{array}{l}20 \text { mm DBM 100. Reference material (Read } \\
1996)\end{array}$ & 71,724 \\
\hline $\begin{array}{l}20 \text { mm HDM 50. Reference material (Read } \\
\text { 1996) }\end{array}$ & 26,389 \\
\hline
\end{tabular}




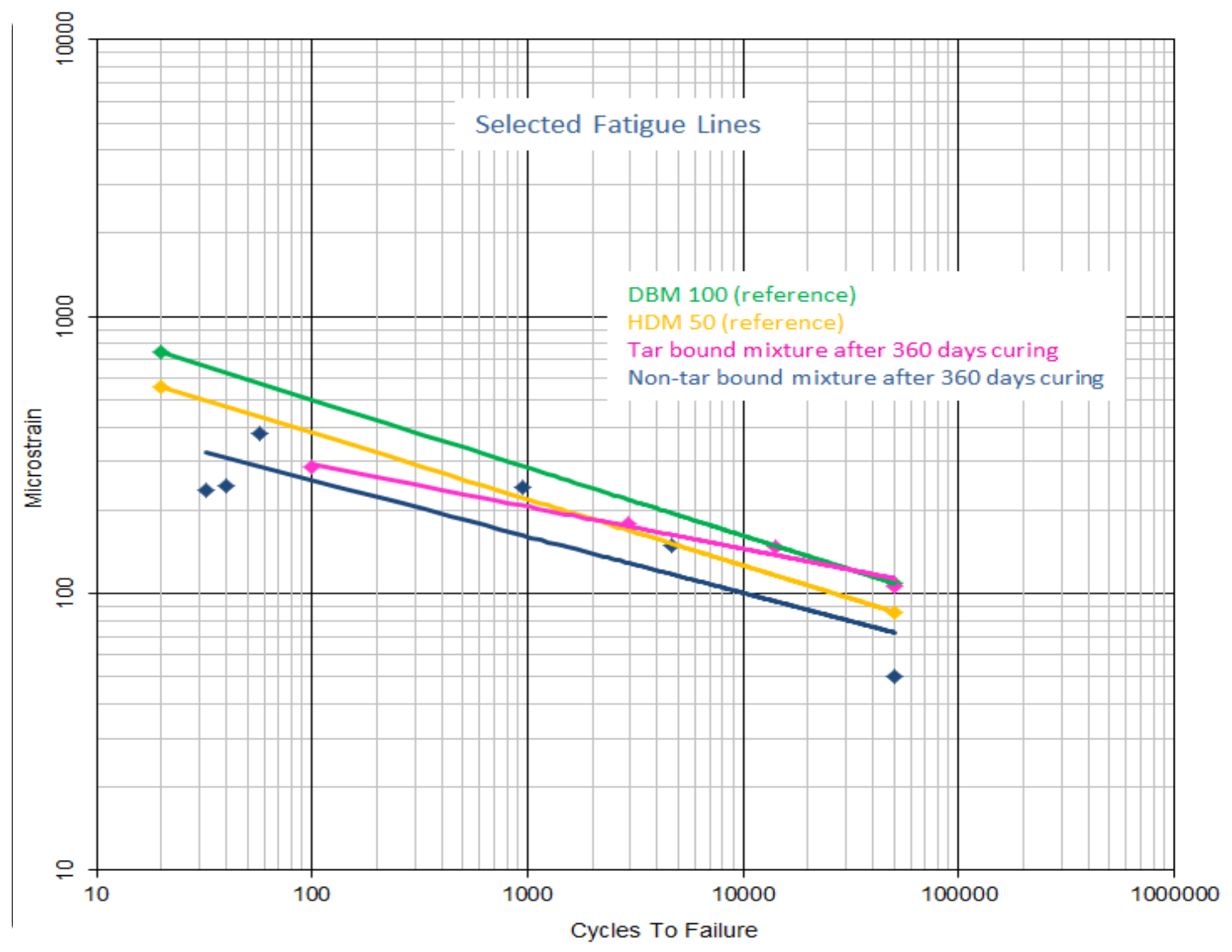

Figure 3. Fatigue lines comparison

The fatigue lines show a comparable performance of the Tar bound (Bottom RAP) mixture with the DBM 100 for a strain around 100. This means that, under the same loading conditions, both materials will have similar performance. In the case of the Non-tar bound (Top RAP) mixture, specimens show lower resistance to fatigue than the tar bound (Bottom RAP) mixture. As already said, this can be due to the addition of CRF, as it is not helping the mixture, being the bitumen not well distributed and affecting the performance of the mixture in terms of fatigue. This also affects the dispersion of the results.

\section{Conclusions}

The results show that tar bound (Bottom RAP) mixture samples achieved the specified requirements for ITSM and ITS. Some variation was found for the ITS tests with the non-tar bound (Top RAP) mixture falling below the specified limits. This is considered to be due to the distribution of the bitumen which could be associated with the incorporation of CRF. Also, results suggest that the incorporation of CRF into foam mix asphalt does not improve the performance in terms of ITS or fatigue, when compared with the tar-bound CRBM mixture, which did not contain CRF. Hence, it is suggested to avoid adding CRF in future works.

Therefore, this test program demonstrates that RAP from RAF Waddington can potentially be recycled into the foamed asphalt which meets specifications for the runway refurbishment works. 
The study also found that samples cured at $40^{\circ} \mathrm{C}$ for 28 days achieved similar ITSM results to those cured for 360 days at $20^{\circ} \mathrm{C}$. With further study, an accelerated curing procedure could be developed.

\section{Acknowledgments}

Many thanks to John Cook, Andrew Horan and Dan Willmott of Defence Infrastructure Organisation for their contribution and permission to publish the data.

The research presented in this paper was carried out as part of the Marie Curie Initial Training Network (ITN) action, FP7-PEOPLE-2013-ITN.

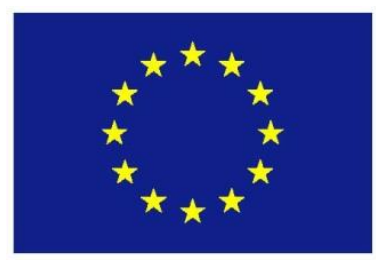

\section{References}

'Lanre, O.O., 2010. A study on the development of guidelines for the production of bitumen emulsion stabilised RAPs for roads in the tropics. Ph.D. thesis, University of Nottingham.

ADEPT, 2013. Managing reclaimed asphalt - Highways and pavements. An ADEPT Guidance Note.

Botasso, H.. et al., 2008. Reciclado de pavimentos asfálticos en frío. Una forma de utilizar totalmente el RAP para el mantenimiento y rehabilitación de la red caminera. Centro de Investigaciones Viales Universidad Tecnológica Nacional Facultad Regional La Plata, Argentina, (1).

British Board of Agreement, Guidelines Document for assessment and certification of thin surfacing system for highways, App. A13, BBA, HAPAS SG3.

CIRIA, 1999. The reclaimed and recycled construction materials handbook,

Cooper, K.E. \& Pell, P.S., 1974. The effect of mix variables on the fatigue strength of bituminous materials,

County Surveyors Society Guidance Note, 2008. Road Materials Containing Tar. , pp.1-10.

Jitareekul, P., 2009. An Investigation into Cold In-Place Recycling of Asphalt Pavement. University of Nottingham. 
Read, J.M., 1996. Fatigue cracking of bituminous paving mixtures. PhD Thesis, University of Nottingham.

Sunarjono, S., 2008. The influence of foamed bitumen characteristics on cold-mix asphalr properties. University of Nottingham.

The Stationery Office, 2005. The Landfill ( England and Wales ) (Amendment ) Regulations 2004 and 2005.

Wirtgen GmbH, 2012. Wirtgen Cold Recycling Technology 1st ed., 